\title{
ANALYSIS OF MATHEMATICAL RELATIONS FOR CALCULATION OF EXPLOSION WAVE OVERPRESSURE
}

\author{
Richard Jankura $^{1}$, Zuzana Zvaková ${ }^{2}$, Martin Boroš ${ }^{3}$
}

\begin{abstract}
The explosion of an explosive system causes primary and secondary effects on people and objects near its site. The most devastating is the pressure effect of the explosion, especially the overpressure. Individual parameters of pressure wave (overpressure size, duration impulse) can be determined by mathematical or virtual modeling or can also be measured under real conditions

The authors focused on the parameters of the positive phase of the shock wave propagating from the source of the explosion towards the object. The article covers the description and analysis of selected mathematical relations, which are used to determine the magnitude of the explosion overpressure. The results are based on selected formulas. The source of the explosion referred in the study is an explosive system containing a reference explosive trinitrotoluene (TNT). TNT is a military explosive that is used as a reference explosive in technical standards dedicated to the certification of explosion-proof elements, and at the same time, a TNT equivalent is known to allow the mass of an explosive charge to be recalculated.

The results obtained by mathematical modeling according to individual approaches have been compared and the possibilities of using computational models in the area of security management and education of security managers have been identified. The results of the study confirm that prediction of pressure wave parameters at different distances and weights can assist security managers in creating attack scenarios and designing a suitable object protection system.
\end{abstract}

UDC Classification: 531, DOI: https://doi.org/10.12955/pns.v1.116

Keywords: blast load, overpressure, mathematical models, scaled distance.

\section{Introduction}

People and objects these days are vulnerable to many threats. The most serious threats include terrorist attacks, which are often carried out using an explosive system. For example, terrorists attacked Oklahoma in the year 1995 (Zhou, 2019). The same is true for accidental explosions that occur in cities. According to Europol, a total of 129 terrorist attacks were carried out, failed or wasted in 2018 within the member states of the European Union (Europol, 2019). All these elements highlights the recency of this threat.

To ensure a higher level of security, more and more commercial property operators are interested in increasing the resilience of buildings and show attention and willingness to address the blast protection (Hofreiter et al, 2016), (Lovecek et al, 2016a). Therefore, it is important to know the course of the shock wave and parameters that affect the resistance of buildings (Zvakova et al, 2016). There are several options by which it is possible to determine the parameters of the pressure wave. These may be analytical or empirical methods based on experimental data, or semi-empirical methods based on basic physical phenomena (Seman et al, 2019). This paper focused on numerical calculations of pressure wave parameters, especially overpressure of the blast pressure wave. There are many suggested solutions for the prediction of blast wave parameter studies (Karlos \& Solomos, 2013), (Draganić et al, 2018), (Karlos et al, 2016), (Swisdak, 2020). These are based either on theoretical analysis, numerical calculations or many experimental tests. The present study compared the results of several numerical models developed by different researchers. The correct use of these models can help security managers in securing objects against the threats associated with explosives and explosive systems.

\section{Pressure wave characteristics}

An explosive blast produces a shock wave. It is characterized by a rapid increase in pressure above atmospheric pressure at the beginning of its course. Consequently, the pressure wave reaches the maximum value and then a phase of decline occurs. This is a positive shock wave impulse. Subsequently, the decline in pressure continues until the negative phase called as a negative impulse of the shock wave. At that time a vacuum is generated for a short period, resulting in the drawing of steam and air from the environment towards the epicentre. There is a balance of forces once the pressure reaches the atmospheric pressure level. The whole process takes place in very short time interval, in the order of one-hundredth of a second (Jangl \& Kavický, 2012), (Figuli et al, 2017). The ideal shock wave is depicted in the following Figure 1.

\footnotetext{
${ }^{1}$ University of Žilina, Faculty of Security Engineering, Žilina, Slovakia, richard.jankura@fbi.uniza.sk

${ }^{2}$ University of Žilina, Faculty of Security Engineering, Žilina, Slovakia, zuzana.zvakova@fbi.uniza.sk

${ }^{3}$ University of Žilina, Faculty of Security Engineering, Žilina, Slovakia, martin.boros@fbi.uniza.sk
} 


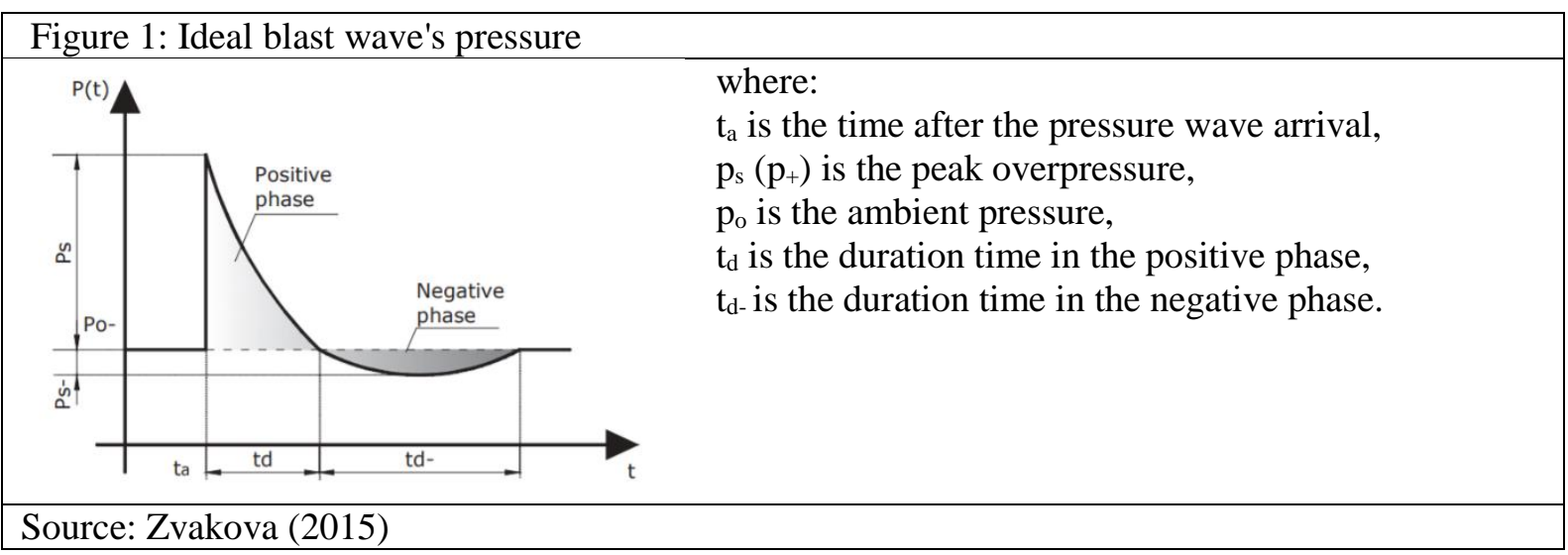

The most significant destructive effect on objects happens during the positive phase of the blast wave and overpressure. Therefore, the paper further discusses the positive phase of the explosion wave and its parameters, such as calculating the value of the overpressure at different distances from the site of explosion.

The calculation of the pressure wave value (Figuli et al, 2016) at different distances is based on the scaled distance and dimensionless characteristics. Using these relationships, it is possible to evaluate shock waves without laborious and demanding measurements. This theory is based on the law of the third root. This law states that two equal charges of the same explosive and geometry but different masses detonating in the same atmosphere, produce very similar shock waves at the same scaled distances (Z) (Karlos \& Solomos, 2013). This relationship is expressed by the equation 1.

$$
Z=\frac{R}{\sqrt[3]{W}}\left(\text { in } \mathrm{m} / \mathrm{kg}^{1 / 3}\right)
$$

where:

- $\mathrm{R}$ - is the distance from the detonation source to the point of interest [m]

- $\mathrm{W}$ - is the weight (mass) of the explosive [kg]

Two parameters that influence the explosion environment the most are the charge weight (W) and the distance $(\mathrm{R})$ between the source of the explosion and the target object. The charge weight $(\mathrm{W})$ is defined as the weight of TNT in kilograms. If another explosive is used, its mass may be calculated using the TNT equivalent (Karlos \& Solomos, 2013). Therefore, for different distances and weights of the charge, they can be transformed into a characteristic distance measure, known as the Hook's Law. The value of the blast pressure also depends on the type of explosion. The possible types of explosions with their parameters are described below.

\section{Blast loading types}

The types of explosion can be distinguished into three basic types, which depend on the relative position of the source of the explosive and the structure to be protected. These are three types of explosion (Karlos \& Solomos, 2013):

- Free-air bursts: The explosive charge is detonated in the air. The blast waves impinge directly onto the structure without prior interaction with other obstacles or the ground.

- Air bursts: This explosive charge is also detonated in the air. The blast waves impinge onto the structure after having interacted first with the ground, Mach's reflection is created.

- Surface bursts: The explosive charge is detonated at the ground surface. The blast waves immediately interact locally with the ground and impinge onto the structure.

Each of these types of the explosion has high load characteristics of the structure, as reflections and other phenomena along the blasted way may significantly change the intensity of the wave (Karlos et al, 2016). The present study discussed the surface explosion as commonly in case of a terrorist attack, a bomb is used on the surface of the ground.

\section{Calculation of the blast pressure}

There are several solutions to predict the pressure wave parameters. Shock wave parameters primarily depend on the characteristics of the environment in which the wave propagates, the charge weight and the explosive parameters (Kinney \& Graham, 1985). The effects of blast waves on the object depend on 
the pressure $\mathrm{p}_{+}$. This section describes several numerical models that can be used to calculate explosion wave overpressure using scaled distance.

Each blast wave is characterized by a set of parameters that can be calculated based on various technical manuals developed mainly by the military community, e. g. Department of Defense, US (2008) and Department of Homeland Security, US (2011). Other formulations for the calculation of these explosion parameters have been developed by a few researchers like Brode (1955); Henrych (1979); Jangl \& Kavický (2012) and Kinney \& Graham (1985). The main objective of most of these studies is to calculate the parameters that characterize the positive phase of the explosion wave (Karlos et al, 2016). The following empirical equations are based on the scaled distance described above.

According to Kinney \& Graham (1985), it is possible to calculate the overpressure based on the equation below. This calculation is based on a chemical explosion. It is used extensively for computer calculation purposes.

$$
p+=p_{o} \frac{800\left[1+\left(\frac{Z}{4.5}\right)^{2}\right]}{\sqrt{1+\left(\frac{Z}{0.049}\right)^{2}} \sqrt{1+\left(\frac{Z}{0.32}\right)^{2}} \sqrt{1+\left(\frac{Z}{1.35}\right)^{2}}} \text { (in kPa) }
$$

Where $p+$ is explosion overpressure, $p_{o}$ is ambient pressure (Atmospheric pressure is 101,325 kPa) and the item $\mathrm{Z}$ is "scaled distance" is described above.

Another formulation is according to Mills (1987). Based on scaled distance, he established the equation (3) below.

$$
\Delta p+=\frac{1772}{Z}+\frac{114}{Z^{2}}+\frac{108}{Z^{3}}(\text { in } \mathrm{kPa})
$$

The consequent option is to use the Sadovsky formula (Jangl \& Kavický, 2012). The formula is designed for the explosion in the air. In the surface explosion, the charge $\mathrm{W}$ is equal to twice the actual mass.

$$
\Delta p+=\frac{0.076}{Z}+\frac{0.255}{Z^{2}}+\frac{0.650}{Z^{3}}(\text { in } \mathrm{MPa})
$$

For $1 \leq \mathrm{Z} \leq 15$

According to Henrych formula, the value of the overpressure can be expressed as follow (equation 5). For an explosion on the ground surface, it is assumed with twice the actual weight of the charge W (Jangl \& Kavický, 2012).

$$
\Delta p+=\frac{0.0662}{Z}+\frac{0.405}{Z^{2}}+\frac{0.3288}{Z^{3}}(\text { in MPa) }
$$

For $1 \leq \mathrm{Z} \leq 10$

Another possibility is to calculate the maximum explosion pressure defined by the Kavicky-Figuli (2016). The equations differ for different values of scaled distances.

$$
\Delta p+=\left(\frac{0.202}{Z}+\frac{0.224}{Z^{2}}+\frac{1.182}{Z^{3}}\right) 0.5 e^{0,03 R}(\text { in } \mathrm{MPa})
$$

For $1 \leq \mathrm{Z} \leq 10$

$$
\Delta p+=\left(\frac{0.202}{Z}+\frac{0.224}{Z^{2}}+\frac{1.182}{Z^{3}}\right) 0.5(\text { in MPa) }
$$

For $\mathrm{Z}>10$.

The succeeding formula comes from various Russian authors and includes elements of American results. The calculation can be used for the surface explosion, where the focus is placed at most $20 \mathrm{~m}$ above the ground surface (Jangl \& Kavický, 2012).

$$
\Delta p+=\frac{0.1}{Z}+\frac{0.43}{Z^{2}}+\frac{1.4}{Z^{3}} \text { (in MPa) }
$$

Kingery-Bulmash (1984) established equations for estimating excessive pressure. Test using explosives weighing less than $1 \mathrm{~kg}$ to more than $400000 \mathrm{~kg}$ have been carried out to determine the resulting equations. The authors used curve fitting techniques to represent data by polynomial equations (UN, 2015). Therefore, the equation allows calculation for a free-air burst at scaled distances ranging from 0,05 to $40 \mathrm{~m} / \mathrm{kg}^{1 / 3}$ and surface burst parameters at scaled distances 0,06 to $40 \mathrm{~m} / \mathrm{kg}^{1 / 3}$. The equation (9) is shown below.

$$
Y=C_{0}+C_{1} U+C_{2} U+C_{3} U \ldots \ldots C_{n} U
$$


where:

- $\mathrm{Y}$ - common logarithm of air explosion parameters (metric) (pressure or pulse).

- $\mathrm{C}_{0,1, \text { etc. }}-$ Constant, are defined through the least-squares fitting of the calculated $\mathrm{b}$ - coefficient values.

- $\mathrm{U}=\mathrm{K}_{0}+\mathrm{K}_{1} \mathrm{~T}$

- $\mathrm{K}_{0,1 \text { etc. }}-$ Constant.

- $\mathrm{T}$-common logarithm of distance (m).

The numerical values of the constants "C" and " $\mathrm{K}$ " are values for the equivalent of $1 \mathrm{~kg}$ TNT (UN Saferguard, 2015).

This equation has a long calculation process. Moreover, it is complicated and requires many constants to be calculated. This equation has been simplified and designed by Swisdak (2020) and Jeon et al (2017), where the variable $U$ was omitted and only 5 constants were defined. The calculation using this equation differed from Kingery-Bulmash equation by only $1 \%$.

Another important step in determining the parameters of a pressure wave is its duration $\left(t_{+}\right)$. It can be calculated according to the following relationship (Zhou, Wang, \& Li, 2019):

$$
t_{+}=\frac{980 \cdot\left[1+\left(\frac{Z}{0.54}\right)^{10}\right]}{\left[1+\left(\frac{Z}{0.02}\right)^{3}\right] \cdot\left[1+\left(\frac{Z}{0.74}\right)^{6}\right] \cdot \sqrt{1+\left(\frac{Z}{6.9}\right)^{2}}}\left(\text { in ms }^{-1}\right)
$$

A significant characteristic is the overpressure impulse $\mathrm{I}_{+}$. Assuming a simplified shape of the curves, that is, the resulting area is a triangle, the impulse can be expressed as a simple shape (Janovský, 2004):

$$
I_{+}=\frac{1}{2} \cdot \Delta p_{+} \cdot t_{+}\left(\text {in } \mathrm{kPa} \cdot \mathrm{ms}^{-1}\right)
$$

If it is not a simplified pressure waveform, the overpressure impulse is expressed by the integral.

$$
I_{+}=\int_{0}^{t_{+}} p \cdot d t
$$

The positive phase of the shock wave represents the time the pressure acts on the object. The impulse characterizes the area under the pressure curve. The measurement of the total energy acting on an object can be calculated as an impulse. In this work, we focused only on measuring the value of pressure on which other calculations depend. The negative phase is neglected in these calculations. The negative phase is filling the gap behind the explosion wave.

\section{Results}

In the study the possibility of using individual mathematical equations on specific examples has been verified. The calculations are oriented to determine the overpressure generated by the explosion according to the eight mathematical models mentioned in the previous section. The first part of the calculation determined the overpressure at a constant distance of $5 \mathrm{~m}$ from the site of the explosion for different weights of the TNT. The second part of the calculations determined the overpressure at a constant charge weight of $0.1 \mathrm{~kg}$ TNT for different distances from the explosion site.

The calculations monitored the change in the size of the calculated blast pressure at different distances from the explosion site and different weights of the charge. The results served to identify the application of mathematical relationships in the security management of protected objects and the designing of optimistic, basic and pessimistic security breach scenarios (Lovecek et al, 2016b), (Siser et al, 2017).

Table 1: Value of overpressure at $5 \mathrm{~m}$ distance and different TNT weights

\begin{tabular}{|c|c|c|c|c|c|c|c|c|c|}
\hline \multirow{2}{*}{$\begin{array}{c}\text { Mass of } \\
\text { explosive [kg] }\end{array}$} & Kinney & Mills & Sadovskij & Henrych & $\begin{array}{c}\text { Kavicky - } \\
\text { Figilu }\end{array}$ & $\begin{array}{c}\text { Russian } \\
\text { authors }\end{array}$ & $\begin{array}{c}\text { Kingery- } \\
\text { Bulmash }\end{array}$ & $\begin{array}{c}\text { Kinney- } \\
\text { Graham }\end{array}$ \\
\cline { 2 - 9 } & \multicolumn{7}{|c|}{ Pressure (kPa) } \\
\hline 0.1 & 9.066 & 12.43 & 9.8 & 9.9 & 10.8 & 14.1 & 13.38 & 9.08 \\
\hline 0.5 & 19.63 & 27.1 & 21.1 & 22 & 24.65 & 32.3 & 29.35 & 19.66 \\
\hline 1 & 29.24 & 40.34 & 30.6 & 32.1 & 34.16 & 48.4 & 43.18 & 29.28 \\
\hline
\end{tabular}

Source: Author

The Table 1 summarizes max. blast pressure determined by individual mathematical models at a constant distance for different weights of the TNT charge. 
The following Figure 2 depicts the results from Table 1.

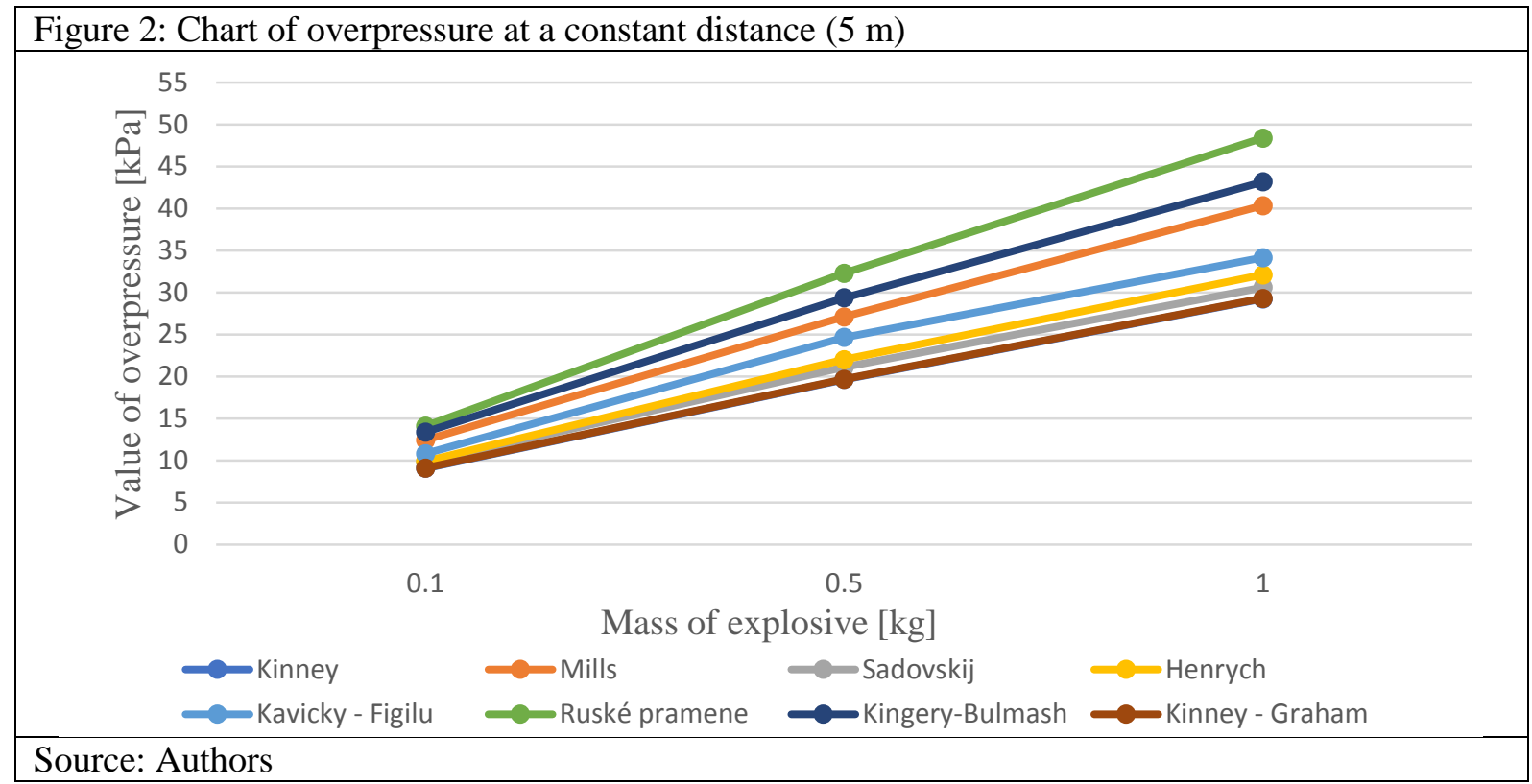

The results show that with a lower explosive mass $(0.1 \mathrm{~kg})$ the dispersion of the result is less than with an explosive mass of $0.1 \mathrm{~kg}$. The highest values of overpressure are determined according to Russian sources, while the lowest values are according to the mathematical model from Kinney.

The following Table 2 summarizes max. blast pressure determined by individual mathematical models at a constant charge mass and different distances from the explosion site.

\begin{tabular}{|}
\hline Table 2: Value of overpressure at 0.1 kg TNT and different distances \\
\hline \multirow{2}{*}{ Distance [m] } & \multicolumn{7}{|c|}{ Mathematical models } \\
\cline { 2 - 9 } & Kinney & Mills & Sadovskij & Henrych & $\begin{array}{c}\text { Kavicky - } \\
\text { Figilu }\end{array}$ & $\begin{array}{c}\text { Russian } \\
\text { authors }\end{array}$ & $\begin{array}{c}\text { Kingery- } \\
\text { Bulmash }\end{array}$ & $\begin{array}{c}\text { Kinney - } \\
\text { Graham }\end{array}$ \\
\cline { 2 - 9 } & \multicolumn{8}{|c|}{ Pressure (kPa) } \\
\hline $1 \mathrm{~m}$ & 174.87 & 251.89 & 155.2 & 150.9 & 134.06 & 279.1 & 239.45 & 175.14 \\
\hline $2 \mathrm{~m}$ & 38.71 & 53.35 & 39.5 & 41.3 & 39.14 & 63.9 & 56.44 & 38.79 \\
\hline $5 \mathrm{~m}$ & 9.066 & 12.43 & 9.8 & 9.9 & 10.8 & 14.1 & 13.38 & 9.08 \\
\hline
\end{tabular}

Source: Author

The change of the calculated pressures at different distances of an explosive weighing $0.1 \mathrm{~kg}$ is shown in the following Figure 3.

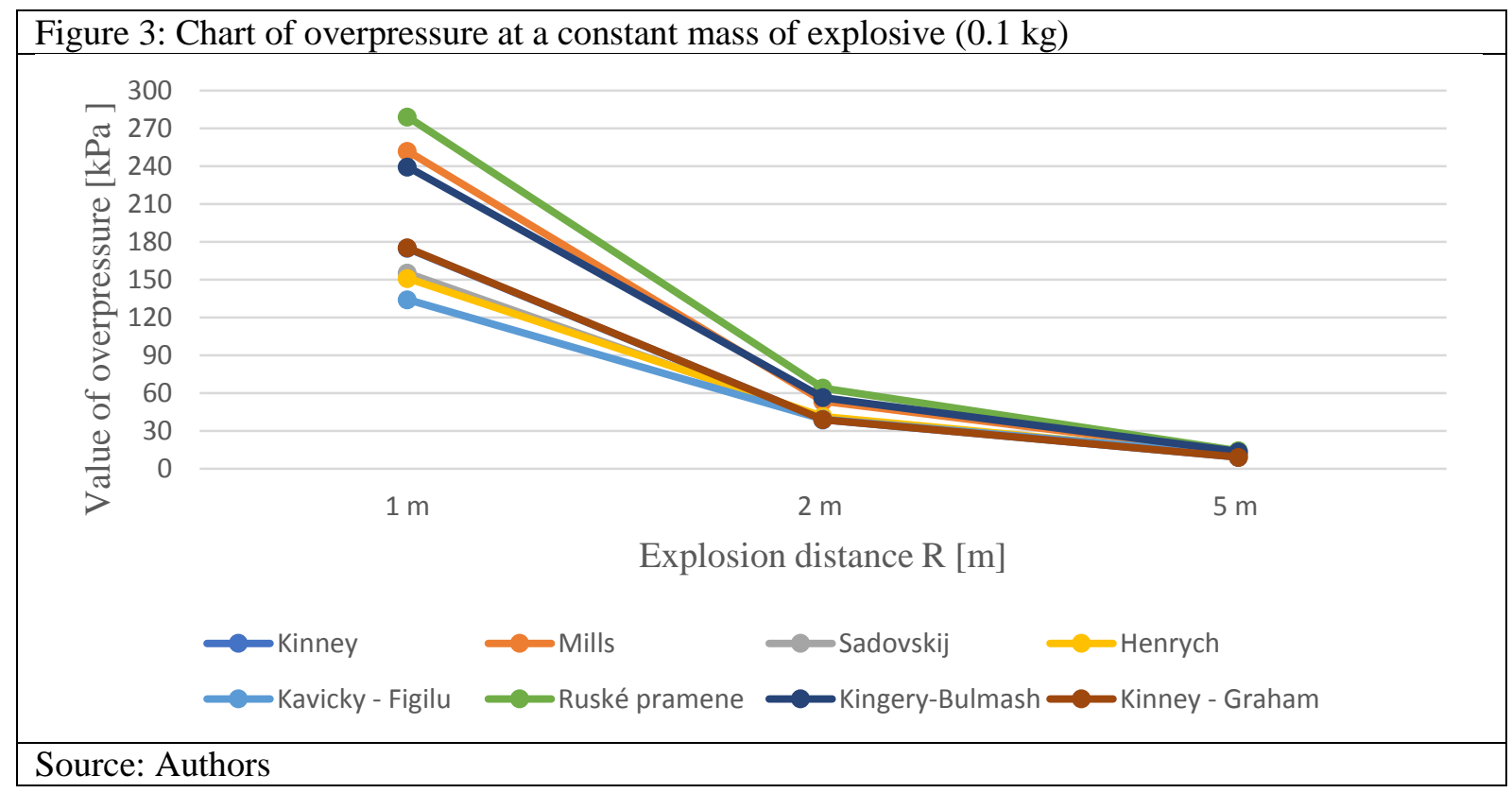


Figure 3 illustrates that the overpressure differences are highest at small distances $(0.1 \mathrm{~m})$. Conversely, very similar results are observed at a pressure at a distance of $5 \mathrm{~m}$. If we consider the reflected overpressure, the values would be much higher. According to Kingery and Bulmash's calculation, at 1 $\mathrm{m}$ the reflected pressure value would be $845 \mathrm{kPa}$, at $5 \mathrm{~m}$ it is $28.35 \mathrm{kPa}$.

The results revealed that reflected pressure values differ from each other, even if these are based on the same or very similar basis. Many computational processes use Kingery-Bulmash results, which were also used in the US standard UFC 3-340-02 (Department of Defense US, 2008). In practice, it would be necessary to unify the individual mathematical and empirical estimates of the value of blast pressures. On the other hand, the results do not differ so much at longer distances. In any case, it is necessary to think about which of the calculations to use for the estimation in the design of the object protection system (Vel'as et al, 2016). The findings have confirmed that mathematical models can be used to create attack scenarios.

The final results, which have been calculated, may differ in an explosion on the ground surface, as there is an immediate interaction between the earth and the blast wave. This is a hemispherical wave. If the ground were a solid surface, the generated pressure would be twice higher than the calculated pressures. However, as ground absorption occurs, the value of pressure is approximately 1.7 to 1.8 times higher (Karlos \& Solomos, 2013). Sadovksy (2004) and Henrych (1979) recommend doubling the actual mass weight of explosives in the calculation. The results in the present study are based on the actual mass of explosive. Thus, the course of the pressure wave is also strongly influenced by the density of the buildings, etc.

\section{Conclusion}

Object security is one of the highest priorities of many organizations (Hofreiter et al, 2016). It is the responsibility of the security managers to safeguard the objects against an attack by an explosive system or from another source that could cause a pressure load on the object. Therefore, it is necessary to know the course of the shock wave and to predict the value of blast pressure which can affect the objects. The article described numerical models, which are used to determine the overpressure parameters at different charge mass. All equations use scaled distances for their calculation. After the characteristics of individual mathematical models, two cases of their application were analyzed. In the first case, the distance of the explosive varied and the weight of the explosive was constant. In the second case, the mass of explosive varied at the same distance. The results showed the variance of these calculations for different cases. It can be argued that at greater distances the results are the least different. Based on several investigations, the Kingery-Bulmash method can be considered reliable (Karlos et al, 2016), as confirmed by our analysis, where the calculated blast pressure values were closer to the average. Individual mathematical models can be used to estimate the amount of pressure load on the object, based on attack scenarios that will help the security manager to appropriately design security measures.

\section{References}

Brode, H. L. (1955). Numerical solutions of spherical blast waves. Journal of applied physics, 26(6), 766-775, doi: https://doi.org/10.1063/1.1722085

Department of Defense, US (2008, December 02). Structures to resist the effects of accidental explosions. (02.December 2008). Unufied Facilities Criteria (UFC 3-340-02). Retrieved from: https://tinyurl.com/yyjmzj5k

Department of Homeland Security, US (2011). Reference Manual to Mitigate Potential Terrorist Attacks Against Buildings (2nd ed.). Buildings and Infrastructure Protection Series. Retrieved from: https://tinyurl.com/y22qng3w

Jeon, D., Kim, K., \& Han, S. (2017). Modified equation of shock wave parameters. Comunication 2017, 5(3), 41.

Draganić, H., Varevac, D., \& Lukić, S. (2018). An overview of methods for blast load testing and devices for pressure measurement. Advancements in analysis and design of protective structures against extreme loadings,1- 20,doi: https://doi.org/10.1155/2018/3780482

Figuli, L., Jangl, S., Papan, D. (2016). Modelling and Testing of Blast Effect On the Structures. IOP conference series: earth and environmental science, 44 (5), 052051.

Figuli, L., Zvakova, Z., \& Bedon, C. (2017). Design and analysis of blast loaded windows. 12th International scientific conference of young scientists on sustainable, modern and safe transport, 192, 177-182.

Henrych, J. (1979). The dynamics of explosion and its use. Elsevier Science Publisher, USA.

Hofreiter, L., \& Zvakova, Z. (2017). Theoretical aspects of critical infrastructure protection. Durability of Critical Infrastructure, Monitoring and Testing, ICDCF 2016, 139-147.

Hofreiter, L., Byrtusova, A., Zvakova, Z., \& Jangl, S. (2016). Ontological aspects of security protection. 3rd international conference on Management innovation and business (ICMIBI 2016), 2(58), 9-14. 
Jangl, Š., \& Kavický, V. (2012). Ochrana pred účinkami výbuchov výbušnín a nástražných výbušných systémov. Žilina: Jana Kavická-KAVICKY.

Janovský, B. (2004). Působení vzdušných rázových (tlakových) vln na zařízení a osoby. Univerzita Pardubice, KTTV.

Karlos, V., \& Solomos, G. (2013, February 10). Calculation of blast loads for application to structural components.

Luxembourg: Publications Office of the European Union. Retrieved from: https://core.ac.uk/download/pdf/38628317.pdf

Karlos, V., Solomos, G., \& Larcher, M. (2016). Analysis of the blast wave decay coefficient using the Kingery-Bulmash data. International journal of protective structures, 7(3), 409-429, doi: https://doi.org/10.1177/2041419616659572

Kingery, C. N., \& Bulmash, G. (1984). Technical report ARBRL-TR-02555: Air blast parameters from TNT spherical air burst and hemispherical burst. U. S. Army Ballistic Research Laboratory, MD.

Kinney, G. F., \& Graham, K. J. (1985). Explosive shocks in air. New York: Springer Science \&Business Media.

Lovecek, T., Ristvej, J., Sventekova, E., Siser, A., \& Velas, A. (2016a). Currently required competencies of crisis and security managers and new tool for their acquirement. 3rd 3rd International conference on management innovation and business innovation (ICMIBI 2016), 2(58), 3-8.

Lovecek, T., Vel'as, A., \& Durovec, M. (2016b). Level of protection of critical infrastructure in the Slovak Republic. Production management and engineering sciences, 163-168.

Mills, C. A. (1987). The design of concrete structures to resist explosions and weapon effects. Proceedings of the 1st Int. Conference on concrete for hazard protections, Edinburg, UK.

Sadovsky, M. A. (2004). Mechanical effects of air shock waves from explosions according to experiments. In: Physics of explosions: symposium No. 4. Moscow: AN SSR.

Seman, M. A., Syed Mohsin, S. M., \& Jaini, Z. M. (2019). Blast load assessment: RC wall subjected to blast load. IOP Conference series: Earth and Environmental Science, 244 (1), doi:https://doi.org/10.1088/1755-1315/244/1/012007

Siser, A., Lovecek, T., \& Maris, L. (2017) Simulation of possible assault vectors in an attack using a real-life waterworks object as a use case. 12th international scientific conference of young scientists on sustainable, modern and safe transport, 192, 794-799.

Swisdak, M. M. (2020, January 14). Simplified kingery airblast calculations. Retrieved from: https://apps.dtic.mil/dtic/tr/fulltext/u2/a526744.pdf

EUROPOL. (2019, March 20). Terrorism Situation and Trend Report. Retrieved from: doi:10.2813/788404

UN Saferguard (2015, February 01). Formulae for ammunition management (2nd ed.). International ammunition technical guidelines. Retrieved from: https://unoda-web.s3.amazonaws.com/wp-

content/uploads/assets/convarms/Ammunition/IATG/docs/IATG01.80.pdf\#page=10

Vel’as, A., Zvaková, Z. \& Svetlík, J. (2016). Education and lifelong learning opportunities in the private security servis in Slovak republic. Edulearn16: 8th international conference on Education and new learning technologies, 6517-6523.

Zhou, X. Q., Wang, \& Li, L. (2019). Dynamic damage assessment of float glass under blast loading. Advances in Structural Engineering, 22(11), 2517-2529. Retrieved from: https://www.researchgate.net/publication/332818774_Dynamic_damage_assessment_of_float_glass_under_blast_loading Zvaková, Z., \& Figuli, L. (2015). Blast resistance of fenestration. Comparative European Research, (p. 4).

Zvakova, Z., Figuli, L., Kavicky, V., \& \& Jangl, S̆. (2016). Security zones for improvised explosive devices using ANFO explosive. In Transport means-proceedings of the 20th international scientific conference, 1100-1104. 